\title{
STUDENTS PROBLEM IN TRANSLATING PRAGMATIC EQUIVALENCY
}

Fakhrurrazi

Fakhrurrazi.amin@gmail.com

\begin{abstract}
The objective of the study is to analyze students' problem in pragmatic equivalence from Source Language to Target Language. The research applied qualitative method, data collected through questionnaire, interview, and observation. To process the data, interactive model of Miles and Huberman was applied to find out the result of the research. The subject of the study was the sixth semester students of English Education Department who are taken a translation class. The result showed that there are several problems faced by students on pragmatic equivalence from Source Language to Target Language in translation class. Those problems are coherence process, implicature/idiom, language structure, quality and velocity. And they faced the problem with many factors including on lack of understanding and mastering the material while translation learning occur. Based on these finding it can be concluded that has faced the problem in pragmatic equivalence.
\end{abstract}

Key word: Pragmatic equivalence, Source Language and Target Language.

\section{A. INTRODUCTION}

In general, English translations, either from English to Indonesia or vice versa lately are very popular. This may be due to the growing public awareness of English as an international language in globalization era. Due to the popularity of the current translation, a translator should be able to analyze the Source Language (SL) well to produce correct translation. English as a communicatin tool there must be various words in the form of implied words which has hidden meaning. Therefore, translator is hoped to be able to match Source Language (SL) to Target Language (TL) to get the actual message. The main problem in the process 
of translation is about meaning which will occur when the process is in progress, it is not translation as a product. As (Hatim \& Munday, 2013) said that one of the key problems for the analyst was in actually determining whether the ST meaning had been transferred into the TT It is clear that meaning is the key problem whether meaning of the Source Language (SL) text is accurately transferred into the Target Language (TL).

Translation process involving two different languages and cultural structures. Naturally the content message from Source Language (SL) must be delivered to target language which has different language structure from source language. Morover it is is always marked by cultural gap of the source language and the target language (Sajarwa, 2017). Accordingly, it will lead to some pragmatic shift which need to find solution such as resolving coercion, the problem of vagueness, and incompatibility, seeking reference and the task of enriching all incomplete information, able to obtain implicitly implied meaning for something explicit.

The implicit meaning of the word should be sought for its true meaning behind its explicit meaning. And in the content of an explicit and implicit proposition, it must also appear in the context of whether the utterance was born. Therefore, the translation cannot be one hundred percent the same as the source text. Especially, the translation in pragmatic equations that contain hidden elements that it difficult to find the equivalent words from the Source Language (SL) to the Target Language (TL).

The difficulty with translation problems is in finding an equivalent match or equivalence between the source and recipient languages or the Target Language (TL), thus requiring more interpretive translation 
activities at that level, to produce the correct translation. As Baker statement in (Panou, 2013) that there are five different kinds of equivalence, that is, at the level of word, phrase, grammar, text and pragmatics.

Thus, translation is not only replacing the source text into another language, but transfering the equivalent meaning or message and manifesting a reasonable translation into Target Language (TL).

\section{B. Definition of Translation}

Generally, translation is a process of rendering meaning, ideas, or messages of a text from one language into another language. In more detail it can be said that translation as transfering message of the source language text into the target language accurately (Sajarwa, 2017). There are some considerations which follow this process, which mainly related to de accuracy, clarity and naturalness of the meaning, ideas, or messages of the translation. It means that it is an important thing to consider whether the readers of the target text accept equivalent information as the readers of the source text do.

In line with equivalent in translation, the most prominent definitions of translation is stated by Newmark, who defines translation as "rendering the meaning of a text into another language in the way that the author intended the text (Newmark, 1988). This definition stresses on rendering meaning of the Source Language (SL) text into the Target Language (TL) text as what is intended by the author.

Nida and Taber, on the other hand, state that "translation consists in reproducing in the receptor language the closest natural equivalent of the source language message" (Atasheneh \& Naeimi, 2015). This definition is more comprehensive than the previous ones. Nida and Taber explicitly state that translation is closely related to the problems of languages, meaning, and equivalence. 
From the definitions mentioned above, it is found that translation is a process which is intended to find meaning equivalence in the target text. In this case, translators are faced with text as unit of meaning in the form of sets of words or sentences. It mean that language which is used is unit of meaning in discourse which can be understood by the participants of the communication. So, the main problem in the process of translation is about meaning which will occur when the process is in progress, it is not as a product. Hatim and Munday also suggest that "one of the key problems for the analysis was in actually determining whether the source text meaning had been transferred into the target text (Hatim \& Munday, 2013)." It is clear here that meaning is the key problem, whether meaning of the Source Language (SL) text is accurately transferred into the Target Language (TL).

\section{The Concept of Equivalence in Translation}

Something that we say in one language can have the same value (the same worth or function) when it is translated into another language. (Panou, 2013) equivalence is a relation of "equal value" between an ST segment and a TT segment and can be established on any linguistic level from form to function. The relation between the source text and the translation is then one of equivalence (equal value), no matter whether the relation is as the level of form, function, or anything in between. Equivalence does not say that language is the same, it just says that values can be the same.

The concept of equivalence has been particular concern to translation scholars since it has been inextricably linked with both definitional and practical aspect of translating.

\section{a. Pragmatic equivalence}


Pragmatic is the study of utterance meaning, sentences which are used in communication and also the study of meaning in language interaction between a speaker and hearer. Pragmatic equivalence refers to words in both languages having the same effect on the readers in both languages. According to Baker, form the variety of notions that are central to this particular area of language study, Baker have chosen two which she believe to be particularly helpful in exploring the question of 'making sense' and in highlighting areas of difficulty in cross-cultural communication (Baker, 2011). These are coherence and implicature.

\section{Coherence}

Coherence is a network of relations which organize and create a text: cohesion is the network of surface relations which link words and expressions to other words and expression in a text, and coherence in the network of conceptual relations which underline the surface text. Both concern the way stretches of language are connected each other. in the case of coherence, they are connected by virtue of conceptual or meaning dependencies as perceived by language users.

The coherence of a text is a result of the interaction between knowledge presented in the text and reader's own knowledge and experience of the world, the latter being influenced by a variety of factors such as age, sex, race, nationality, education, occupation, and political and religious affiliations. Coherence is mostly receiver-centered. It depends on the ability of the hearer/reader to interpret a stretch of language on the basis of his/her expectation and experience of the world. Which in their turn are influenced by the society he/she lives in. for example:

"He looked like a Frodo coming down the mountain. The hobbit was walking slowly and singing to himself". 
One has to know that "Frodo" and "the hobbit" are the same person, which means that he/she must have read the novel Lord of the Rings, seen the movie drawn from it, or at least heard about on of the two. If a translation of the sentence were addressed to a public who is not likely to have done any of the above mentioned things, the translator would probably have to intervence and modify it, for instance in the following way:

"He looked like Frodo the hobbit coming down the mountain. He was walking slowly and singing to himself" (Baker, 2011).

Thus coherence is not really a property of text but of the event/situation and of the people and things involved in it. A dialogue can be coherent to one observer or participant and not coherent to another.

2. Coherence and process of interpretation: implicature

Baker said that Grice uses the term implicature to refer to what the speaker/writer means or implies rather than what he or she literally says. Implicature is not to be confused with non-literal meaning. For instance with idiomatic meaning.(Baker, 2011). Idiomatic meanings is conventional, and is interpretation depends on a good mastery of the linguistic system in question rather than on a successful interpretation of a particular speaker's intended or implied meaning in a given context. For instance in the following exchange:

A. Shall we go for walk?

B. Could I take a rain check on that?

The interpretation depends on knowing the meaning of the expression "take a rain check" in American English, and will be "if you don't mind, we'll do it another time".

While in the case of: 

A. Shall we go for a walk?
B. It's raining.

The answer could be interpreted as: “No, thanks, I don't want to get wet", or "okay, but let's take an umbrella", etc.

According to Grice mentioned by Baker, who is mainly concerned with spoken language, a speaker can signal an implied meaning conventionally or non-conventionally.(Baker, 2011). Implied meaning which is not signaled conventionally drives from the cooperative principle and its maxims of Quantity, Quality, Relevance and Manner:

(a) Quantity

- Make your contribution as informative as is required.

- Do not make it more informative than is required.

(b) Quality

- Do not say what you believe is false.

- Do not say that for which you lack adequate evidence.

(c) Relevance/ Relation

- Make your contribution relevant to the current exchange.

(d) Manner

- Avoid obscurity

- Avoid ambiguity

- Avoid prolixity

- $\quad$ Be orderly

The maxims of the cooperative principle can be flouted for various but, generally speaking, we assume that an utterance that follows a question provides an answer to that question. Therefore, we will try an interpretation that suits the question. 
Again, the inferences we draw will depend on our knowledge of the world, of the participants in the discourse and of the situation. Implicatures, then, are pragmatic inferences which allow us to understand a stretch of language beyond its literal meaning by taking into account the Cooperative Principle. This complicates the task of a translator who might knowingly or unknowingly eliminate certain possible interpretations of the original text.

Grice suggest a number of factors which can contribute to our success of failure to interpret implicatures, and they are:

1. The conventional meanings of the words and structures used (mastery of the language) and the recognition of any references involved.

2. The Cooperative Principle and its maxims.

3 . The context of the utterance.

4. Other elements of background knowledge.

5. The fact that the above mentioned elements are available to both participants (Baker, 2011).

\section{Translation Equivalence for SL and TL}

A tremendously attractive converse of the notion of equivalence can develop in (Baker, 2011) who seems to offer a more detailed list of conditions upon which the concept of equivalence can be defined. She explores the notion of equivalence at different levels, in relation to the translation process, including all different aspects of translation and hence putting together the linguistic and the communicative approach.

Equivalence that can be emerge at work level and above word level, when translating from one language into another. Baker acknowledges that, in a bottom-up approach to translation, equivalence at word level is the first element to be taken into consideration by the translator. In fact, when the translator starts analyzing the SL s/he looks at the words as 
single units in order to find a direct 'equivalence' term in the Target Language (TL).

Baker gives a definition of the term word since it should be remembered of the single word can sometimes be different meanings in different languages and might be regarded as being a more complex unit or morpheme. This means that the translator should pay attention to a number of factors when considering a single word, such as number, gender and tense.

\section{E. METHODOLOGY}

This research was designed qualitatively. Qualitative research was focused on the study of social phenomena and on giving voice to the feelings and perceptions of the participants under study (Barone, 1992). Hence, this using of qualitative approach in this study was to match between the empirical realities with the occurred theory by using descriptive method. Then the aim of the reserach was to explain students' problems as research object without trying or coordinating to the objects of the research. This research attempted to analyze students' problem in pragmatic equivalence from Source Language (SL) to Target Language (TL). The research was conducted at sixth-semesters' students of English Department, State Institute for Islamic Studies (IAIN) Langsa, The research applied three instruments; (1) Interview, (2) Questionnaire, and (3) Observation to get the data from research subject about the problem faced in case of pragmatic equivalent in translation.

Data analysis technique was a method or way to process a data into information, that the characteristics of the data becomes easy to understand and also useful to find solutions to problems. According to Miles and Huberman, data analysis was organized on the site it was affirmed that the columns in a timeline matrix were arranged with the time period, in the order of stages, so that can be seen when the symptoms certain happened. 
The basic principle was the chronology (Rep, 1960). (Creswell, 2012) also said that the basic principle of qualitative analysis was to manage systematic, orderly, structured and meaningful data. And generally, it can be seen that the technical analysis of data was a method to process a data into information, so that the characteristics of the data become easy to understand and also used to find solutions to the problem of a study. Data analysis in this research using data analysis technique developed by Miles and Huberman. To present the data for easy understanding, then the steps data analysis used in this research is Analysis Interactive Model of Miles and Huberman, which some part that was data reduction, data display and conclusion drawing or verification.

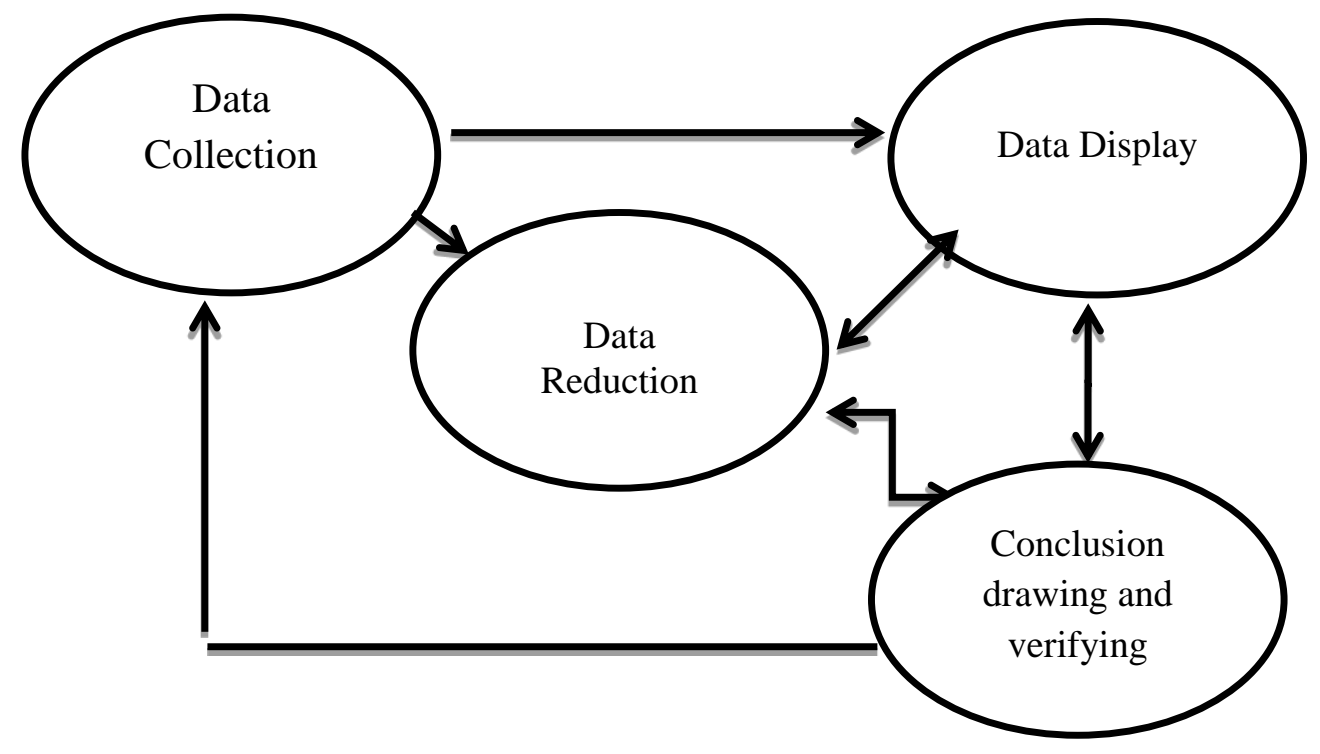

Figure 3.1. Model analisis data Interactive adapted fom (Miles \& Huberman, 1994) 


\section{Data Reduction}

Data reduction refers to the process of selecting, focusing, simplifying, abstracting, and transforming the data that appear in written-up field notes or transcriptions.

2. Data Display

The second major flow of data analysis activity was data display. Miles and huberman also quoted that generally, a display was an organized, compressed assembly of information that permits conclusion drawing and action.

3. Conclusion Drawing and Verification

The third stream of analysis activity was conclusion drawing and verification, from the start of the data collection, the qualitative analyst was beginning to decide what things mean-is noting regularities, patterns, explanations(Miles \& Huberman, 1994).

\section{F. FINDING AND DISCUSSION}

\section{Finding}

After conducting the research, the researcher was found out that there were several problems faced by students in translation class while doing translation the text from Source Language (SL) to Target Language (TL). Based on the data obtained there were still many students were not understand about coherence process in adding and subtracting words in translating from Source Language (SL) into Target Language (TL) of pragmatic equivalence. The process of coherence itself was a practice of decomposition, moving and changing word delicately and logically from Source Language (SL) to Target Language (TL). The students facing the problem on coherence shown by the following data "I never heard about coherence, so I never used it when translating".Based on the respondents' 
expressions, it visible that there was a weakness in understanding and knowing about coherence in translation. Respondents did not know about coherence especiallyin used it in the translation process.

Then, the next expression obtained from the respondent, "I've heard about coherence, but never knew that the coherence process could be used to translate". From the data stated that respondents had heard about coherence, but still did not know and understood that coherence could be done in the translation process. Thus, it can be seen that students still do not understand the process of coherence and how to apply it in translating idiom. Thoughcoherence was an important element that cannot be separated in the translation process. Especially in case of nterpreting a word that has a hidden meaning.

Moreover, the data from questionnaire also shown the same thing given to respondents. In this case, the researcher uses an idiom in a sentence for a statement, From the first sentence stated in the questionnaire, as follow:

SL: The test was piece of cake.

\section{TL: Soal itu sangat mudah.}

As it was mentioned in questionnaire: A piece of cake which that word translation means weresepotong kue. In this case, the sentence: The test was a piece of cake, if it translated without having to do with coherence process it's so illogical, but by understanding of using coherence which mean extending the idea of the word, a piece of cake here mean "it's very easy".

Thus, it may conclude that it can be seen from the results of interviews and questionnaire above that students faced problems in the process of coherence due to lack of knowledge about the process of coherence itself. Moreover, in this case, in pragmatic equivalence of Source Language (SL) and Target Language (TL) in translation, the process of 
coherence was something that students really need to understand in order to translate idioms properly and correctly and more regularly. It wasknownthat the process of coherence was balancing a word by moving, adding, and reducing words and giving an idea from Source Language (SL) to Target Language (TL). As a resultthat the Target Language (TL) results seem more logical and easily understood by the reader.

Besides, the researcher found the students also faced the problem in the process of translating implicature, explicitly translating an implied meaning or idiom meaning. The results of interview with respondents, as the following: "I have never translated idioms, nor do I know what idioms were". From the statement, it was seen that there were still students who did not translate the idiom, and did not even know what the idioms were. On the other hand, the next respondent stated:"Once translated an idiom and it was very difficult for me". And from this next statement states that students find it difficult when translating an idiom from the source language into the target language.

From the data above, it can be seen that they still do not understand the meaning of idioms or implied words in the translation, and it shows that one of the difficulties in translation was translating an idiom. The data on the difficulties in translating idioms also supported by the results of questionnaires, the second sentence example which contains idioms, that was:

SL: There are a good dealof luxury car.

TL: Ada banyak mobil mewah.

From the sentence of questionnaire, 'a good deal' in SL was an idiom, then in TL 'a good deal' means 'lots' or 'much'. And from this case, students are still very difficult to understand an idiom or word that has a different meaning if translated it using a dictionary. 
Moreover, this problem was also found by researchers from the results of observations, there were few sudents whom still not understand about idiom. One of the idioms specified by the lecturer was 'cat and dog' with the phrase 'the rain outside like cat and dog'. When the lecturer asks students, students seem confused translating, and then one of the students says what were the relationship between 'rain, cat and $d \mathrm{gg}^{\prime}$. From the above finding, it was seen that there were still many students who do not known about idioms and implied words included in the translation process. And it was not only in English that has idioms, but Indonesian also had many words that have hidden meanings such as idioms.

The next data found by researchers was about mastering vocabulary and language structures. This data was obtained from the results of the interview, where the respondents stated that: "I lack mastery of vocabulary so it's difficult when I want to present". From the respondents' expressions, they showed that they still experienced weaknesses in vocabulary mastery, making it difficult for them to face the process of translating Source Languages (SL) to the Target Language (TL).

Then the next respondent stated: "Because the language structure between Source Language (SL) and Target Language (TL) was different, it becomes difficult to translate it from Source Language (SL) to Target Language (TL)". From the statements of respondents, it was shown that they had difficulty understanding the differences in language structure between the source language and the target language. And in this case, differences were an obstacle to differences in the structure of the language so that it disrupts their fluency in the process of their translation. From these statements it can be seen that the vocabulary and structure of the language were the difficulties and problems they faced, because of their lack of knowledge of 
these problems, assembly them difficult when translating the Source Language (SL) to the Target Language (TL).

The data above was also supported and found by researchers from observations, where when the process of translating Source Language (SL) into Target Language (TL) students must rely on dictionaries and smart phones. Some even saw the results of their friend's translation. As a result, it can be seen the students still complicated to master a vocabulary, they need to see on smartphone to translate from Source language (SL) into Target Language (TL).

In addition, the data from observation shown that almost students experienced it.

\section{SL: What is your name? \\ TL: Siapa nama kamu?}

And the other example of language structure:

SL: I see.

\section{TL: Saya paham.}

From the example and statement above, it can be seen that the vocabulary was related to language structure, considering that without extensive vocabulary mastery, one cannot use structure and language functions in communication comprehensively. It was a translation process that was not immediately changing the word but it must still be ensured that the meaning of the original source should not be the same and understood.

The next problem faced by students was the quality and velocity of translation. These results were obtained by researchers from observations, where students when faced and did the exercise to translate short texts in 
English, must take a long time to complete the translation. Even with the comsulted todictionaries and smart phones, to translate source languages into their target languages takes a very long time. This problem was also found by researchers from the interview results to the respondent. This was where the respondent reveals that:" The problem when translating English into Indonesian at a very short duration of time". From the expression shows that, the time or duration in the translation process was also a factor that becomes a difficulty and obstacle for students. Especially in translating an English text into Indonesian.

Then the next respondent revealed:"Because in order to get quality translation results, I need to take a long time to complete the translation". Then from the next phrase, pointing out that in producing good and regular translations, it must take a long time to complete, although it only translates a simple sentence from English to Indonesian.From the statements above, it can appear that quality and velocity were important things that must also be mastered by students, seeing that translating a text from the source language into the target language was difficult, so learning the translation stages was one way that must be mastered.

\section{Discussion}

From the research finding there were components which were discussed in the research finding. The component consists of difficulty in coherence process and impicature. As it was shown in finding that students lack in understanding about coherence process of adding and subtracting word, and in extending the idea. Baker stated that coherence was a network of relations which organize and create text, and in the network of conceptual relations which underline the surface text.(Baker, 2011). Based on the statement that coherence process was a link that organized and made or changed a text, which underlines the initial text or the source of the language. And in this case, coherence was closely related to pragmatic equivalents, because the pragmatic equivalent itself was a study that 
discusses the equivalence of the meaning of the Source Language(SL) to the Target Language (TL).Thus, coherence correspondence to the system of explicit and implicit connective elements of the next immanent entity. Based from Engebresten believes that coherence, it was hard for a text which involves differences to have as strong coherence as a text with a fixed, linear structure.

Then in the process of adding, Bell stated that the information added through the meaning must be rise to "releasing to it" situation of accreditation for the purpose of building a clear context for the reader to process. Beside, From the explanation, by adding an information or idea or also a word to the translation, it can create the meaning more relevant and clear so that it was more easily understood by the reader. Clearly it can produce high-quality translations without having to eliminate messages from the source language itself.Moreover, in this case of the process of coherence, (Beaugrande, 1991) noted that the text was coherent which was to say that the content was organized in a way that was easy for humans to read and understood. In this study, states that coherence was an important process in translation, where a text has a coherence or network of relationships that regulates content so that the translation results were easily understood by the reader.

Thus, from the theoretical statements above, it can be concluded that the process of coherence and the addition of words was an important component in the translation process. Especially in the case of translating idiomatic meanings, because there was a continuity of sense among the knowledge of expressions of the texts. Furthermore, the problem was implied in the case of idioms where intake idioms were a difficult for students in the translation. Chaer argues that idioms were 'units of language whose meaning cannot be drawn from the general grammatical rules that applied in that language or cannot be predicted from the lexical 
meaning of the elements that make it up Error! Reference source not found. From the definition expressed by Chaer, it can be seen that idioms were a form of text or an expression that cannot be translated by their own volition or follow the word.However, Chaer added that the overall meaning of the idiom can still be searched for it was relationship or purpose between the Source Language (SL)and the Target Language (TL) historically comparative and etymological, so, this means there are predictable idioms of lexical meaning and their elements.

Besides, Kridalaksana stated that idiom was a construction of elements that choose each other; each member has meaning that exists only because of the other or the construction whose meaning was not the same as the combined meaning of its members. As an example of a questionnaire that was previously explained in the results of the study, specifically, a piece of cake which means a piece of cake as a whole, not the same as cake. From the explanation of the definition of the idiom, it can be seen that an idiom was a unit of language whose meaning was different from the meaning of the components forming it.

Then, Mary McGee Wood defines that idioms are complex expressions which mean that they were not composition and the overall shape was unproductive. From these definitions, idioms are components that cannot be translated into the meaning of the constituent elements or words of words, because in an idiom it has a message behind a simple word.Therefore, it can be concluded that idioms were a difficult component in translation, as obtained by the data that students have difficulty in translating an idiom meaning in which idioms were words that have a message and hidden meaning in it or referred to as implicature. 
Furthermore, in the problem of mastery of vocabulary and structure of language, the students still faced the weakness in mastering and understanding due to differences between the source language structure and the target language. Hatim and Munday noted that koller stated, in particular, contrastively whereas equivalence ST-TT pairs and context deals with equivalent items in specific (Hatim \& Munday, 2013). From this explanation, the comparison between the system and the structure of the source language with the target language can be described in contrast and then equalized in the context of the source language and the target language in a elatedly.

Moreover,Nababan noted that each language has a syntactic, syntagmatic, lexical, and morphological structure that was different from other language systems. From this explanation it can be said, the translator was very demanded in understanding the source language and discussing the target and not just the search process of the equivalent words, seeing that translation was not easy because each language has their own system.Then the mastery of vocabulary Nurgiyantoro stated that the vocabulary was a very important component that can be called the key to learning a foreign language because of the wealth of one's vocabulary determines the quality of a person's language skill. From this expression, it was clear that vocabulary was a very important component that must be mastered by English students especially in the scope of translation.

From the thesetheoretical above, it can be concluded that the importance of mastering the vocabulary and the structure of language in the field of interpreting source languages into the target language, especially in the case of translating idiomatic meanings. This was where 
the vocabulary and structure of language were the basic components that really need to be studied, understood and mastered by English students.

Then, on the next issue wasabout quality and velocity for students when translating idiomatic meanings from Source Language (SL) into the Target Language (TL). Which in the results of the data that has been explained in the research finding that students need a long time to get good and appropriate translation results. Nababan stated that the quality of translation was based on aspects of accuracy, acceptability, and readability. From the phrase, it can be explained that to get a quality translation, students or translators were required to start reading the entire text contained in the source language before changing it into the target language. Viewed from the side of students' problems in the duration of time to get a quality translation, there must be a technique to overcome them.

Machali stated that translation techniques can use procedures by changing the point of view, focus, and cognitive categories of the target language. Thus, from this explanation, it can be explained that the technique of finding quality and fast translations can be completed by changing the point of view and focusing the categories contained in the target language.

Moreover,Luther in Simatupang that "Translation is not everybody's art". Translating, for Luther was an art that cannot be owned by everyone. This shows that translating was not an easy thing. He needs complex skills. As an art, as well as the sculpture of music, art, dance, translating was intuitive and therefore cannot develop without knowledge, training and experience.From the these theoretical explanations above, it can be concluded that the problem of quality and velocity in translation must master the techniques in translation, 
recognized that translation was a matter in which there were various problems faced by students. The practice of translating in the case of idiom meanings from discussing to the target language can measure the quality and duration of speed in translation.

\section{G. CONCLUSSION AND SUGGESTION}

Based on finding and discussing in the previous chapter, the researcher would like to point out some conclusion and proposes some suggestions concerning the research finding as follow:

1. According to research finding and discussion it may conclude that students faced several problem in translating the pragmatic equivalence from Source Language (SL) to Target Language (TL) in translation class, the problems faced by students include in the process of coherence, implicature/idiom, mastery of vocabulary and language structure, as well as on quality and velocity. There were several problems which must be mastered in pragmatic equality in the field of translation from a Source Language (SL) to Target Language (TL).

2. The causes in these problems above werebecause of several factors, specifically lack of knowledge in mastering these problems themselves, and too ignoring that mastering and learning theseproblems was something that must be mastered by students especially English students who clearly involved in the translation process. No more than that, considering that English wascurrently a language that almost all humans throughout the world learn about it.

\section{Bibliography}

Atasheneh, N., \& Naeimi, M. (2015). Theory and practice in language studies. Theory and Practice in Language Studies, 5(3), 541-548. Retrieved from

http://www.academypublication.com/ojs/index.php/tpls/article/ view/tpls0503541548/134

Baker, M. (2011). In Other Words: A coursebook on translation, second edition. In In Other Words: A coursebook on translation. Retrieved from http://www.slideshare.net/abdullahktk2/mona-baker-in-other- 
words-a-coursebook-on-translationroutledge-2011

Barone, T. E. (1992). Beyond Theory and Method: A Case of Critical Storytelling. Theory Into Practice, 31(2), 142-146. https:/ / doi.org/10.1080/00405849209543535

Beaugrande, R. de. (1991). Linguistic Theory The Discourse of Fundamental Works (pp. 1-447). pp. 1-447. China: Pearson Education Limited.

Creswell, J. W. (2012). Educational Research: Planning, Conducting and Evaluating Quiantitative and Qualitative Research (4th Editio). United State of America: Pearson.

Hatim, B., \& Munday, J. (2013). Translation An Advanced Resource Book. In Journal of Chemical Information and Modeling (Vol. 53). https:/ / doi.org/10.1017/CBO9781107415324.004

Miles, M. B., \& Huberman, A. M. (1994). Qualitative data analysis.pdf. Qualitative Data Analysis, pp. 75-80. https://doi.org/10.1007/s10071013-0700-5

Newmark, P. (1988). A Textbook of Translation. In Text.

Panou, D. (2013). Equivalence in translation theories: A critical evaluation. Theory and Practice in Language Studies, 3(1), 1-6. https:/ / doi.org/10.4304/tpls.3.1.1-6

Rep, F. (1960). Book Reviews H . -J . Z I M M E R M A N N R WTH Aachen M. F. MOOP , E University of Stirlvrg Stirring, United Kingdom Critical Heuristics of Social Planning: A New Ap-proach to Practical Philosophy.

Sajarwa, S. (2017). Deconstructing Equivalence in the Translation of Texts from French to Indonesian. Jurnal Humaniora, 29(2), 159. https://doi.org/10.22146/jh.v29i2.24063 